relations, ethnic groups in America, the interplay of politics and economics in America's changing capitalism, and social change in Soviet Russia. In length and quality the contributions are uneven; but some are much below the standard of the rest. What will most impress any reader familiar with Prof. MacIver's own pellucid style, to which Alpert pays a relldeserved tribute, is the extent to which a volume written in MacIver's honour falls short of the high standard of exposition which he set. This is not true of all the essays : that of Prof. George Catlin on the utility of political science, like those by Spitz and Alpert, is happily free from jargon; but there is sufficient evidence in this book to support the charge of atrocious writing that Alpert brings against much American sociology in his own essay.

For that reason, it is difficult to assess the value of the book as a whole. It is not to be expected that the specialist will gather much that is new from such a volume, and the pleasure he finds in a tribute to an esteemed colleague cannot but be marred when the expression of that tribute falls so far short of the standard associated with MacIver. More serious is that, in a book addressed at least to a considerable extent to the general reader, a lapse from high standards of exposition into jargon which is largely unintelligible except to the specialist is unfortunate if not reprehensible. The sociologist is entitled to have his own special terms : indeed, it is essential that he should take particular care to define his terms, in view of the varying and loose meanings which are given to such words as 'freodom' and 'authority' in common parlance, let alone in political debate. If, however, he is to make a real contribution in clarifying the ideas of men and women, he must be particularly careful to present the results of his thinking in language which ordinary men and women can understand, and which will neither confuse nor repel them. That this is possible several of these essays demonstrate, notably those of Thomas Cook on individual liberty and Kingsley Davis on the demographic foundations of national power, in addition to those authors already mentioned; it is also demonstrated by a British writer, Sir Ernest Barker, with whose thought MacIver's has something in common. But there is much in this book that, for the reason just given, will do little to advance public understanding of the vital problem of freedom and control in modern society or, as is perhaps more familiar to us, of the responsible exereise of power.

R. BRIghtMaN

\section{DISEASES OF FARM ANIMALS IN BRITAIN}

Farm Animals in Health and Disease

By Dr. W. R. Wooldridge. Pp. xvi $+463+56$ plates. (London: Crosby Lockwood and Son, Ltd., 1954.) $30 s$. net.

$\mathrm{T}$ HIS book is not a scientific text-book but a serious attempt to produce a book for farmers which gives a sensible and reasoned approach to the diseases of animals. It is not another book which gives a number of disjointed and confusing technical facts along with a larger number of 'home' remedies ; but it tries successfully to put the question of animal disease into a proper perspective. In consequence, it could be read usefully by everyone interested in livestock production.
The book is divided into two parts: the first covers general aspects of animal disease and the second deals with specific troubles. The first part is subdivided into four main chapters: (1) Good health, in which the normal functioning of the body is simply but well described. (2) Ill-health, in which the general signs of ill-health are given and the causes of disease sensibly set out with proper emphasis on factors other than the microbe. (3) The cost of ill-health, which perhaps cannot be estimated as: accurately as one could wish or as the chapter might suggest. (4) The control of disease, which is quite rightly the longest chapter in the section. In this chapter various means of control are well described. The success of legislative and police methods is shown by the complete eradication from Great Britain of cattle plague, bovine pleuropneumonia, sheep pox and scab, rabies and glanders, while foot-and-mouth disease and anthrax are adequately controlled. The control of tuberculosis, swine fever and contagious abortion is also discussed. This chapter also clearly sets out the various aspects of preventive medicine and shows how prevention of disease depends upon early and proper diagnosis, specific vaccines and drugs, good nutrition and management, proper breeding and good pasture management.

The second part deals with the specific diseases of cattle, sheep, goats, pigs, horses, poultry and the rabbit. The chapter on cattle begins with a number of statements of fact regarding numbers of bulls licensed, the amount of food consumed and the economics of the milk and meat trades, and this is followed by a short summary of hygiene on the cattle farm. The third part of the chapter deals with the notifiable diseases, and the information given regarding foot-and-mouth disease and tuberculosis, although brief, is adequate for the purpose. In other sections the calfhood diseases are also adequately described and the attempt to present the predisposing factors is as good as present scientific knowledge permits. The information regarding Johne's disease in cattle could possibly have been more definite regarding the difficulty of control and the inadequacy of the johnin test for this purpose. 'The metabolic diseases of cattle such as milk fever, hypomagnesæmia, acetonæmia and bloat are described briefly, perhaps too briefly, as, for example, in the case of hypomagnesæmia, where greater detail regarding the prevention of the disease by giving additional magnesium either as a mineral supplement or as a pasture fertilizer would have been of practical help to the stockman. Mastitis, contagious abortion and infertility are sufficiently described, although certain features could usefully have been emphasized.

The chapter on sheөp diseases quite rightly relates husbandry and disease, and many excellent examples of this relationship are given (although several of the statements could be debated). It is considered that, taking into account the briefness of the chapter, the description of the diseases of the sheep is adequate, but is not sufficient for those really interested and practised in sheep husbandry.

Despite these criticisms, the book is well written and will be useful as a guide to the stockowner and agriculturist, especially those chapters in part one. The second half of the book could also be useful provided it is not mistakenly used as a reference book to give the answer to all the questions of animal disease.

The book is well produced and has many good photographs.
J. T. S'TAMP 